\title{
Size distribution of commuters' exposure to airborne particulate matter in buses in the UK
}

\author{
W. W. Song \& M. R. Ashmore \\ Environment Department, University of York, UK
}

\begin{abstract}
Traffic is an important source of particle emissions which contribute to urban air pollution around the world. In transport microenvironments particles of various sizes, which can be inhaled and cause serious health effects, are generated from fuel combustion. In this study, the size distribution of commuters' exposure to particles inside public buses was examined in the city of York, UK. Measurements were conducted during the winter, inside different types of buses. Particle number concentrations were measured in four main size classes: $0.3-10 \mu \mathrm{m}, 1.0-3.0 \mu \mathrm{m}, 3.0-7.5 \mu \mathrm{m}$, and $7.5-15 \mu \mathrm{m}$. The correlation coefficients between particle number concentrations for these different size ranges differed for each type of bus. Statistical analysis showed that the different size classes of particles were influenced by different factors. Particles in size class $0.3-1.0 \mu \mathrm{m}$ were affected by the duration at bus stops, number of people active, and outdoor concentrations, but the effect of numbers and activities of passengers in re-suspending particles was the dominant factor for coarse particles.
\end{abstract}

Keywords: transport, particles, exposure, buses.

\section{Introduction}

The size distribution of airborne particles is an extremely important parameter for personal exposure studies in various microenvironments. Particle size distribution is very variable both in time and space, which reflects the stability, behaviour, characteristics and chemical composition of particles.

Epidemiological evidence summarised by WHO [17] suggests that more than 280,000 premature deaths can be attributed to long-term exposure to particles in the 25 countries of the European Union (EU), while short-term exposure to particles also increases the risk of emergency hospital admissions for 
cardiovascular and respiratory diseases. There is evidence that these adverse health effects depend on particle size. Recent epidemiological studies have suggested that particles with a diameter less than $1 \mu \mathrm{m}\left(\mathrm{PM}_{1}\right)$, which can penetrate into the alveolar region of the lungs, can affect lung physiology and cause a higher prevalence of respiratory disease (Issever et al. [11]; Pope [14]). Other studies suggest that reductions in the heart rate of cardiac and hypertensive patients are associated with $\mathrm{PM}_{0.3-1.0}$, while $\mathrm{PM}_{2.5-10}$ is significantly associated with effects in the upper parts of the airways and lungs [3].

Assessment of health effects of particles, and of the benefits of measures to reduce emissions, needs to consider the actual exposure experienced in different micro-environments. Traffic is a major source of fine particles as people travel for work, visits, shopping and other events in cities. Previous studies of personal exposure to particles in transport microenvironments have investigated both private and public transport modes, including car, bus, train, taxi, and tram (e.g. Kaur et al. [12], Gulliver and Briggs [9], Harrison et al. [10], Chan et al. [6], Adams et al. [1], Sitzmann et al. [15], Akbar and Ashmore [2]). These studies indicate that exposure to particles in transport microenvironments is higher than in other indoor microenvironments and at urban monitoring sites.

Although most of these studies have concentrated on exposure to particles in cars, bus is the most popular and frequently used public transport mode in UK cities. Previous studies carried out in the UK of personal exposure to particles in buses [1, 12] were conducted in combination with measurements in other transport modes, as was the study in Hong Kong [6]. These studies did not relate concentrations in buses to particular characteristics of the journeys. In the US, studies have focused on exposure of pupils in school buses (Fitz et al. [7]). Moreover, all these studies focused on measurements of mass concentrations, and no study has determined particle size distributions in buses. Analysis of particle size distribution and number concentration in buses could enhance understanding of how particles behave in buses and assist in assessment of the possible effects on passengers' health.

The objectives of the study were to determine the particle size distribution and number concentrations in different bus microenvironments; to compare the number concentrations of different particle size groups; and to identify significant factors which affect in-bus particle concentrations

\section{Methodology}

\subsection{Selection of routes}

Transport in York is focused on an inner ring road around the historic city centre and a number of radial roads, which link it to the outer ring road. Four typical and popular bus routes were chosen, with contrasting types of buses. On Route 1, single-decker and double-decker buses run between two suburban areas through the city centre. Route 2 is a circular route, which passes the university, hospital, and a major shopping mall, and goes through the city centre; it is operated by both single and double-decker buses. Measurements on Route 1 and 2 were 
conducted in both morning and evening rush hours on weekdays, from 8:00 to 10:00 and 16:30 to 18:00. There was congested traffic, with more commuters on board than at other time periods. Route 3 services a Park \& Ride facility close to the outer ring road, calling at the train station and the city centre, before returning. Two-compartment bendy buses were examined on this route. Route 4 is in a suburban environment, and connects two big shopping malls; a mini-bus is the only type of bus operated. Measurements on Route 3 and 4 were made during the peak pre-Christmas shopping period on weekends and weekdays, from 10:30 to $17: 00$.

\subsection{Instrumentation}

Continuous real-time measurements of particle number concentrations were made using a portable aerosol spectrometer (GRIMM 1.108 dust monitor [8]), which determined particle number counts in different sizes. The monitor classifies particles into 15 different size ranges. Particles are recorded with upper boundaries of $0.3 \mu \mathrm{m}, 0.4 \mu \mathrm{m}, 0.5 \mu \mathrm{m}, 0.65 \mu \mathrm{m}, 0.8 \mu \mathrm{m}, 1.0 \mu \mathrm{m}, 1.6 \mu \mathrm{m}, 2.0 \mu \mathrm{m}$, $3.0 \mu \mathrm{m}, 4.0 \mu \mathrm{m}, 5.0 \mu \mathrm{m}, 7.5 \mu \mathrm{m}, 10 \mu \mathrm{m}, 15 \mu \mathrm{m}$ and $20 \mu \mathrm{m}$. The monitor was held about $20 \mathrm{~cm}$ from the breathing zone, sitting in the middle of buses. The carrying case was used to keep the monitor balanced and steady.

Travel diaries were recorded during each trip, with information that included date, time, route, bus type, bus number, seating position of monitor, number of passengers, the time trips started, number of traffic stops, number of bus stops, number of passengers getting on and off at each bus stop, particular locations the bus passed by, and window status. Data on $\mathrm{PM}_{10}$ concentrations at a monitoring location in the city centre, measured using a TEOM instrument, were obtained for the period of each trip [5].

\subsection{Particle size classification}

Data were divided into four classes based on the characteristics and behaviour of the particles and on correlation patterns in the monitoring data, using the dividing points of $1.0 \mu \mathrm{m}, 3.0 \mu \mathrm{m}, 7.5 \mu \mathrm{m}$ and $15 \mu \mathrm{m}$. Data from the size class $15-20 \mu \mathrm{m}$ were omitted as concentrations were low and erratic.

\section{Results}

\subsection{Overall number concentrations}

Mean number concentrations of particles in the four size classes in different types of buses are shown in Figure 1. The mean number concentrations of particles in size class $0.3-1.0 \mu \mathrm{m}$ range from $73,000 \mathrm{l}^{-1}$ to $141,000 \mathrm{1}^{-1}$, in size class $1.0-3.0 \mu \mathrm{m}$ range from $820 \mathrm{l}^{-1}$ to $4,200 \mathrm{l}^{-1}$, in size class $3.0-7.5 \mu \mathrm{m}$ from 110 $1^{-1}$ to $1,200 \mathrm{l}^{-1}$ and in size class $7.5-15 \mu \mathrm{m}$ from $20 \mathrm{l}^{-1}$ to $90 \mathrm{l}^{-1}$.

Analysis using one-way ANOVA and Tukey post-hoc tests showed no significant differences in number concentrations in the fine particle class $(0.3-1.0 \mu \mathrm{m})$ between bus types, although the highest concentrations were found 
in the bendy bus and circle line bus (Figure 1). For each of the two coarse particle classes, the concentrations in the bendy bus were significantly greater than in all the other bus types. There was a tendency for higher concentrations in the single-decker buses than in the circle line and mini-buses, although this difference was not significant.

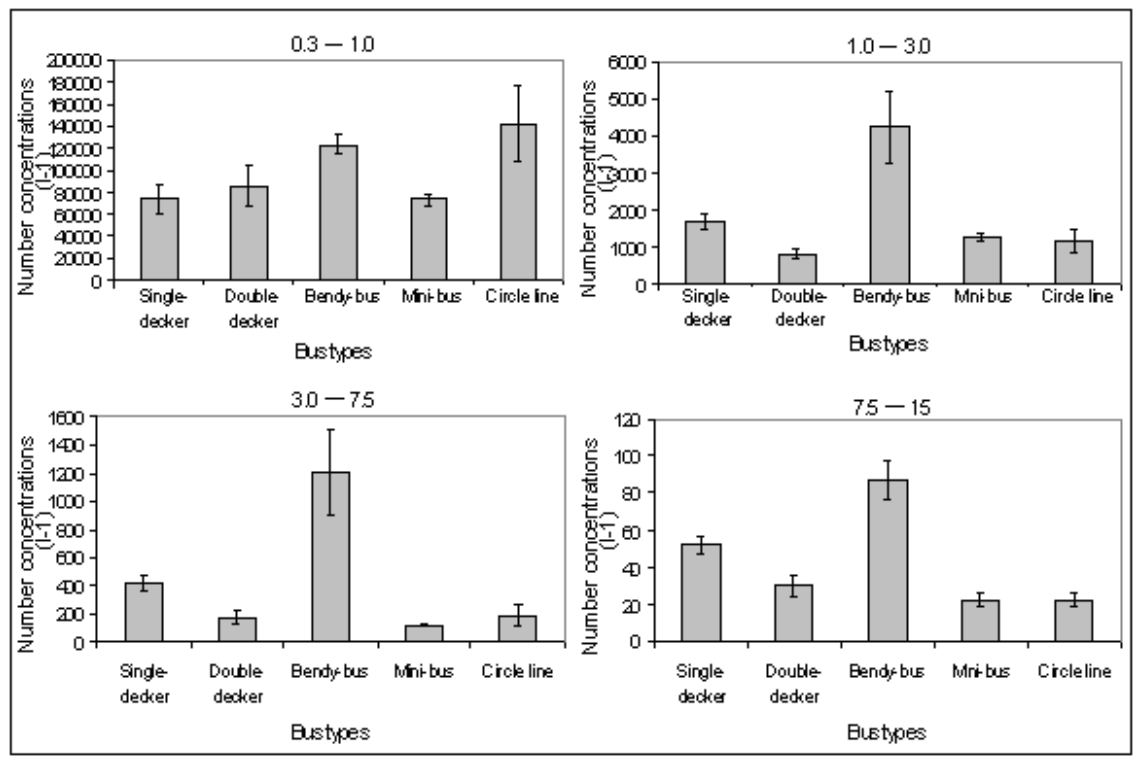

Figure 1: Mean number concentration of four particle size classes in five bus types. Error bars represent the standard error of the measurements, $\mathrm{n}=22$ for single-decker bus, $\mathrm{n}=20$ for double-decker bus, $\mathrm{n}=24$ for bendy-bus, $\mathrm{n}=8$ for circle line bus, $\mathrm{n}=9$ for mini-bus.

\subsection{Correlations of four size classes}

Correlation analysis was employed to assess the strength of the relationships between concentrations in different particle size classes in different types of bus. Table 1 summarizes the correlation matrices for each type of bus. All significant correlation coefficients were positive.

Concentrations in the two coarse particle classes were significantly correlated, except for the mini-bus. Concentrations in the finest particle class were never correlated with those in the two coarse particle classes, and were only correlated

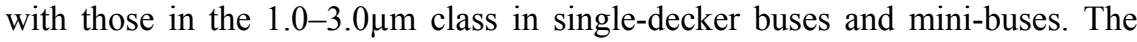
strongest difference between different types of buses is shown by concentrations in the 1.0-3.0 $\mu \mathrm{m}$ class, which were strongly correlated to these of the finest class in single-decker bus and mini-bus $(\mathrm{p}=0.05)$, and to both coarse particle classes $(p=0.01$ or 0.05$)$ for other types of buses. These results strongly suggest that there are different sources of particles for the different size classes. 
Table 1: Correlation matrices of four particle size classes for five types of buses. Vales of $\mathrm{n}$ are as given in legend for Figure 1 .

\begin{tabular}{|c|c|c|c|c|c|c|c|}
\hline $\begin{array}{l}\text { Single } \\
\text {-decker }\end{array}$ & $0.3-1.0$ & $1.0-3.0$ & $3.0-7.5$ & $\begin{array}{l}\text { Double } \\
\text {-decker }\end{array}$ & $03-10$ & $1.0-30$ & $3.0-7.5$ \\
\hline $1.0-3.0$ & $462^{*}$ & & & $1.0-3.0$ & 0.139 & & \\
\hline $3.0-7.5$ & 0.314 & $.960 * *$ & & $3.0-7.5$ & -0.104 & $.871^{\text {*** }}$ & \\
\hline $7.5-15$ & -0.161 & 0368 & $.486^{*}$ & $7.5-15$ & -0.068 & $.759 * * *$ & $.921 * *$ \\
\hline $\begin{array}{l}\text { Bendy } \\
\text { bus }\end{array}$ & $0.3-1.0$ & $1.0-3.0$ & $3.0-7.5$ & Miri-bus & $03-10$ & $1.0-30$ & $3.0-7.5$ \\
\hline $1.0-3.0$ & 0.061 & & & $1.0-3.0$ & $.830^{*}$ & & \\
\hline $3.0-7.5$ & 0.081 & $.984 * *$ & & $3.0-7.5$ & 039 & 0.555 & \\
\hline $7.5-15$ & 0.137 & $.898 * *$ & $891^{* *}$ & $7.5-15$ & -0.176 & -0.281 & 0567 \\
\hline $\begin{array}{l}\text { Circle line } \\
\text { bus }\end{array}$ & $0.3-1.0$ & $1.0-3.0$ & $3.0-7.5$ & & & & \\
\hline $1.0-3.0$ & -0.345 & & & & & & \\
\hline $3.0-7.5$ & -0.382 & $.820^{*}$ & & & & & \\
\hline $7.5-15$ & -0.416 & $.813^{*}$ & $.974 * *$ & & & & \\
\hline
\end{tabular}

* Correlation is significant at the 0.05 level (2-tailed).

** Correlation is significant at the 0.01 level (2-tailed).

*** Correlation is significant at the 0.001 level (2-tailed).

\subsection{Re-suspension of particles}

One possible source that might contribute relatively more to the coarser particle concentrations is re-suspension of particles by passenger activities such as walking, moving bags and touching seats when they get on or off buses. Results from Route 3, which services the Park \& Ride facility, provide the strongest indication of the importance of re-suspension of particles by passengers getting on and off the bus. The example trip presented in Figure 2 was measured in the evening of $4^{\text {th }}$ December 2005. The duration of the trip was about 22 minutes. There were initially 3 passengers on board when the bus departed from the Park $\&$ Ride site, 2 of them got off and 82 more got on in the city centre in the period 16:47:12 to $16: 49: 23$.

As shown in Figure 2, number concentrations of particles in all classes increased from 16:47 and reached peaks at 16:49 or 16.50. This was the time when passengers boarded the bus in the city centre. The concentrations of coarse particles increased about $75 \%$ compared to the previous minute. This increase became progressively less marked for the finer size classes, with very little effect on concentrations in the range $0.3-1.0 \mu \mathrm{m}$.

\subsection{Factor analysis}

Multiple regression analysis was conducted to identify factors which are predictive of concentrations in different size classes, combining data for all bus types. The five factors used in this analysis are summarized in Table 2, which 
also indicates the form of the data and its derivation from diary and other information. All five factors had been shown to be independent of each other in correlation analysis.

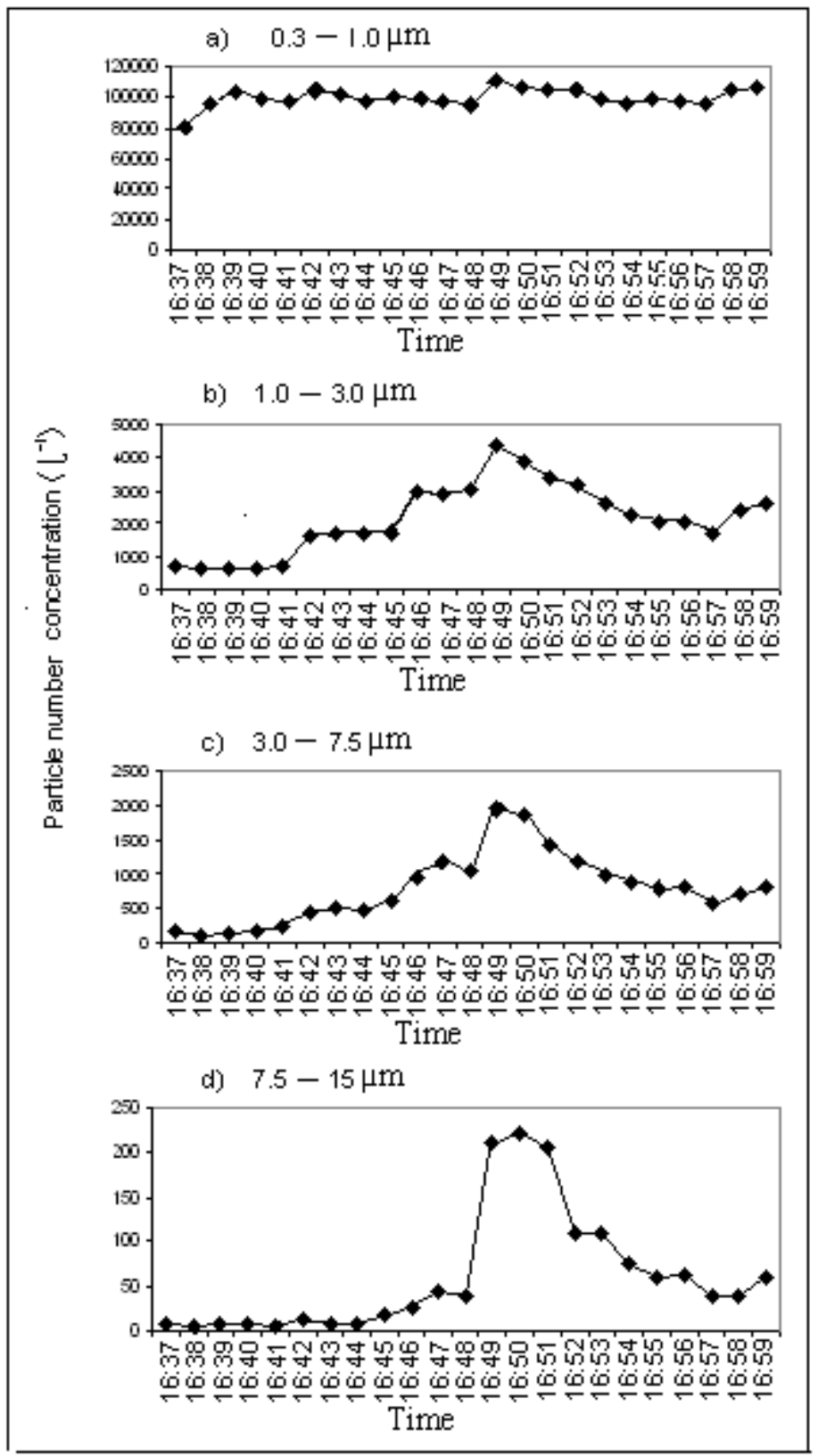

Figure 2: Time-course of particle number concentration $\left(1^{-1}\right)$ in four size classes in the afternoon of $4^{\text {th }}$ December 2005, on Route 3. 
Table 2: $\quad$ Summary of factors, data types, and derivation of data, for multiple regression analysis.

\begin{tabular}{|l|l|l|}
\hline Factors & Data type & Derive of data \\
\hline Number of people active & Quantitative & Number per minute of the trip \\
\hline Duration at bus stops & Quantitative & Proportion of total duration of the trip \\
\hline Ambient PM concentration & Quantitative & Log $_{10}$ transformed concentrations \\
\hline Traffic stops & Quantitative & Number per minute of the trip \\
\hline Time of day & Category & Code of two levels \\
\hline
\end{tabular}

Table 3: $\quad$ Summary of results of multiple regression (all bus types).

\begin{tabular}{|c|c|c|}
\hline Particle size range & Model of best fit & $\mathrm{R}^{2}$ for model of best fit \\
\hline $0.3-1.0$ & 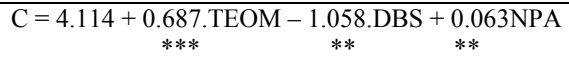 & 0.271 \\
\hline $1.0-3.0$ & $\mathrm{C}=\underset{*}{2.812}+\underset{* * *}{0.071 . \mathrm{NPA}}+\underset{*}{0.051 . \mathrm{NBS}}$ & 0.290 \\
\hline $3.0-7.5$ & $\begin{array}{c}\mathrm{C}=2.162+0.155 . \mathrm{NPA} \\
* * *\end{array}$ & 0.225 \\
\hline $7.5-15$ & $\mathrm{C}=1.355+\underset{* * *}{0.130 . \mathrm{NPA}}$ & 0.321 \\
\hline
\end{tabular}

$* * *: \mathrm{P}<0.001 ; * *: \mathrm{p}<0.01 ; *: \mathrm{p}<0.05$

TEOM: $\log _{10}$ concentration at fixed site monitors $\left(\mu \mathrm{g} \mathrm{m}^{-3}\right)$

DBS: Duration at bus stops

NPA: Ratio of number of people active

NBS: Number of bus stops

Stepwise multiple regression was performed to develop models to predict the number concentrations inside buses, using a backwards model filling procedure. All selected factors were first entered into the model, each factor was tested in turn, and the weakest factor that had the least significance was then removed. To satisfy assumptions of normality, the data of particle number concentration and ambient $\mathrm{PM}_{10}$ concentrations were transformed into $\log _{10}$ values.

The results are shown in Table 3. ANOVA showed that the regression explained a significant proportion of the variation in particle number concentration in each case, although only between $22 \%$ and $32 \%$ of the variation could be explained. Number concentrations in the $0.3-1.0 \mu \mathrm{m}$ class were significantly increased by high outdoor concentrations (TEOM), and more people active on buses, while longer duration at bus stops decreased the number concentrations. The regression coefficient for outdoor concentrations was more significant than that for the other two factors. The significant factors for the 1-3 $\mu \mathrm{m}$ class were NPA and NBS, indicating that particle number concentrations were increased both by the number of passengers and by the number of bus stops. The only factor that significantly increased the concentrations of the two coarse particle classes was NPA, which is probably due to the deposition and resuspension of these larger particles. If there were more passengers getting on or off of the bus, there would be more large particles re-suspended. 


\section{Discussion and conclusion}

Personal exposure to particles in buses in UK cities may only cover a short exposure period compared to other microenvironments, but concentrations may be relatively high. The air exchange rate and penetration rate of outdoor air into buses may be significantly greater than for buildings, because of the frequent opening of doors at bus stops, and the use of air conditioning systems or open windows. Furthermore, the density and frequency of people's movements in a bus are much higher than in offices, day care centres and homes, and may be more comparable to school classrooms, for which high concentrations of coarse particles have also been reported (Stridh [16]). Particle concentrations in buses most likely reflect high outdoor concentrations, often in busy traffic [1], the effects of self-pollution from exhausts (Behrentza et al. [4]), and re-suspension from activities within the bus, but previous studies have not clearly distinguished the contribution of these different sources to in-bus concentrations.

The measurement of number concentrations of particles in different size classes in this study, together with recording of the characteristics of each bus trip, enabled us, for the first time, to infer the contribution of different factors to concentrations of different size particles. According to the multiple regression analysis, the activities of passengers, the number of bus stops and ambient concentrations were the main factors related to the measured concentrations in bus trips. Although only $25-35 \%$ of the variation in mean trip concentrations could be explained by the fitted regression equations, the outdoor concentrations used were only from a fixed city centre site, rather than on the particular bus routes, while passenger movements are likely to be only a crude estimate of actual levels of re-suspension. Extension of our approach to include measurements of concentrations immediately outside the bus, and detailed chemical and physical analysis of the particles, would allow more definitive assessment of the contribution of different sources.

Many previous measurements of personal exposure to particle mass concentrations provide mean values over durations of 8 to 24 hours (e.g. Mohammadyan and Ashmore [13], Stridh [16]), but assessment of the health significance of in-bus exposures must rely on measurements over the period of the actual trip. The study of Adams et al. [1] in London used a high flow personal sampler to measure fine particle $\left(\mathrm{PM}_{2.5}\right)$ concentrations in bus trips of about 1 hour duration. The mean personal exposure of $39 \mu \mathrm{g} \mathrm{m}^{-3}$ was similar in summer and winter and bus concentrations were consistently higher than in car and bicycle trips on the same route. Exposures were significantly higher on trips in the centre of the city, where outdoor concentrations would be higher. However, personal exposures for trips on the same route using buses with open and closed backs were similar, suggesting, as in our study, that penetration of outdoor air was not the only factor affecting in-bus concentrations. A further study in a specific location in central London [12] reported a similar mean personal exposure to $\mathrm{PM}_{2.5}$ in buses $\left(34.5 \mu \mathrm{g} \mathrm{m} \mathrm{m}^{-3}\right)$, and that this was three times higher than concentrations at a local urban background monitoring station and 
$50 \%$ higher than at a local kerbside monitoring station. High ultra-fine particle counts were also found on buses

Although the exposure durations for these studies in buses in London were only about an hour, the $\mathrm{PM}_{2.5}$ exposures exceeded $24 \mathrm{~h}$ mean guidelines for protection of human health set by WHO [17]. Much higher concentrations have been reported on bus trips in Delhi [2]. The results of our study in York suggest that the significance for human health of in-bus exposures will depend on the sources of the particles of different sizes to which passengers are exposed. Since vulnerable groups, such as the elderly and children, tend to be over-represented in bus journeys in the UK, and since government policy seeks to increase use of public transport models such as buses, there is a need to carefully assess the factors influencing exposure to particles in bus trips and their significance for public health.

\section{References}

[1] Adams, H.S., Nieuwenhuijsen, M.J., Colvile, R.N., McMullen, M.A. \& Khandelwal, P., Fine particle $\left(\mathrm{PM}_{2.5}\right)$ personal exposure levels in transport microenvironments, London. UK, Science of the Total Environment, 279, pp. 29-44, 2001.

[2] Akbar, S. \& Ashmore, M.R., Particulate air pollution and respiratory morbidity in Delhi, and its implications, In: Proceedings of the World Congress on Air Pollution in Developing Countries, Vol. II, pp. 52-58, Costa Rica. Imprenta Nacional of Costa Rica, San Jose, 1997.

[3] American Lung Association, Health effects of ozone and particle pollution, State of the Air: 2006. http://lungaction.org/reports/ sota06 heffects.html\#pp

[4] Behrentza, E., Fitz, D. R., Pankratzb, D.V., Sabina, L.D., Colomec, S.D., Fruind, S.A. \& Winera, A.M., Measuring self-pollution in school buses using a tracer gas technique, Atmospheric Environment, 38, pp. 3735 3746, 2004.

[5] Casella ETi, www.air-quality.net

[6] Chan, L.Y., Lau, W.L., Lee, S.C. \& Chan, C.Y., Commuter exposure to particulate matter in public transportation modes in Hong Kong, Atmospheric Environment, 36, pp. 3363-3373, 2002.

[7] Fitz, D., Winer, A., Colome, S., Behrentz, E., Sabin, L., Lee, S., Wong, K., Kozawa, K., Pankratz, D., Bumiller, K., Gemmill, D. \& Smith, M., Characterizing the range of children's pollutant exposure during school bus commutes, Final Report, Contract No. 00-322, California Air Resources Board, Sacramento, CA.

[8] GRIMM, http://www.quantitech.co.uk/images/OCC.PDF

[9] Gulliver, J. \& Briggs, D.J., Personal exposure to particulate air pollution in transport microenvironments, Atmospheric Environment, 38, pp.1-8, 2003.

[10] Harrison, R.M., Thornton, C.A., Lawrence, R.G., Mark, D., Kinnersley, R.P. \& Ayres, J.G., Personal exposure monitoring of particulate matter, 
nitrogen dioxide, and carbon monoxide, including susceptible groups, Occupational and Environmental Medicine, 59, pp. 671-679, 2002.

[11] Issever, H., Disci, R., Hapcioglu, B., Vatansever, S., Karan, M.A., Akkaya, V. \& Erk, O., The effect of air pollution and meteorological parameters in Istanbul on hospital admissions for acute coronary syndrome, Indoor and Built Environment, 14, pp. 157-164, 2005.

[12] Kaur, S., Nieuwenhuijsen, M. \& Colvile, R., Personal exposure of street canyon intersection users to $\mathrm{PM}_{2.5}$, ultrafine particle counts and carbon monoxide in Central London, UK, Atmospheric Environment, 39, pp. 3629-3641, 2005.

[13] Mohammadyan, M. \& Ashmore M. R., Personal exposure and indoor $\mathrm{PM}_{2.5}$ concentrations in an urban population, Indoor and Built Environment, 14, pp. 313-320, 2005.

[14] Pope, C.A., Epidemiology of fine particulate air pollution and human health: biologic mechanisms and who's at risk? Environmental Health Perspectives, 108, pp. 713-723, 2000.

[15] Sitzmann, B. Kendall, M., Watt, J. \& Williams, I., Characterisation of airborne particles in London by computer-controlled scanning electron microscopy, Science of the Total Environment 241, pp. 63-73, 1999.

[16] Stridh G., Total dust exposure and size distribution of air borne particles in day-care centres, schools, and offices. Indoor Air, pp. 97-102, 2002.

[17] WHO, How large a risk to health is air pollution in the European Region, and is there evidence indicating effective measures to reduce it? Summary of a HEN network member's report, 01 April 2006. World Health Organisation, Geneva. http://www.euro.who.int/HEN/Syntheses/short/ $\underline{20051128 \_1}$ 